\title{
Prospecção Científica e Tecnológica Aplicada ao Conceito de Estações de Tratamento de Esgoto Sustentáveis
}

\author{
Scientific and Technological Prospecting Applied to the Concept of \\ Resources Recovery in Wasterwater Treatment Plants
}

\author{
Fabio Campos ${ }^{1}$ \\ Marcelo A. Nolasco ${ }^{1}$ \\ ${ }^{1}$ Escola de Artes, Ciências e Humanidades da Universidade de São Paulo, São Paulo, SP, Brasil
}

\begin{abstract}
Resumo
O conceito de estação de tratamento sustentável de esgoto envolve a prática de recuperação e de reaproveitamento de seus subprodutos, dotando-os de valor de mercado. Com o intuito de verificar o envolvimento do meio acadêmico, o estudo realizou prospecção científica em base de dados e em escritórios de registros de patentes compreendendo os últimos 20 anos. A análise da prospecção evidenciou uma tendência positiva em relação às pesquisas na área, com ênfase ao reúso de esgoto, tendo o predomínio da China seguida pelos EUA em termos de publicações; destacandose a participação brasileira entre os 10 primeiros países em termos de publicações sobre o assunto. Quanto à análise patentária, verificou-se um número considerável de registros com descritores que caracterizam o tema deste estudo, com tendência crescente desde 2015. Conclui-se, portanto, que o assunto é inovador e promissor, apresentando-se como uma interessante área tanto para o meio acadêmico como para a geração de novas tecnologias e produtos para a sociedade.
\end{abstract}

Palavras-chave: Recuperação de Nutrientes. Tratamento de Esgoto. Saneamento.

\begin{abstract}
The concept of sustainable WWTP involves the practice of recovery and reuse of its by-products, providing them with market value. In order to verify the engagement of the academic environment, the study carried out scientific prospection in databases and patent registration offices comprising the last 20 years. The analysis of prospecting showed a positive trend in relation to research in the area, with emphasis on sewage reuse, with the predominance of China followed by the USA in terms of publications; the Brazilian participation among the top 10 countries in terms of publications on the subject is highlighted. Regarding the patent analysis, there was a considerable number of records with descriptors that characterize the theme of this study, with an increasing trend since 2015. It is concluded, therefore, that the subject is innovative and promising, presenting itself as an interesting area both for the academic environment, as for the generation of new technologies and products.
\end{abstract}

Keywords: Nutrient Recovery. Sewage Treatment. Sanitation.

Área Tecnológica: Saneamento. Sustentabilidade. 


\section{Introdução}

A Organização das Nações Unidas (ONU) estabeleceu em 2015, com o aval dos grandes líderes mundiais, o documento Agenda 2030 para o Desenvolvimento Sustentável, contendo os 17 Objetivos de Desenvolvimento Sustentável (ODS), que envolvem as dimensões humana e planetária (ONU-BRASIL, 2019a). Entre os ODS, destacam-se as metas 6.2 e 6.3 que versam acerca do objetivo de alcançar o acesso ao saneamento e à higiene adequados e equitativos para todos até o ano 2030, assim como a melhora da qualidade da água, reduzindo-se a poluição e aumentando substancialmente o reúso seguro do esgoto (ONU-BRASIL, 2019b).

A introdução desses objetivos vem ao encontro da crescente discussão de questões antigas, como aquelas decorrentes dos problemas relacionados à poluição das águas provocadas pelo lançamento inadequado de esgotos sanitários nos corpos hídricos. Nesse cenário, é possível observar avanços significativos no aumento do número de estações de tratamento de águas residuárias, aliado ao aumento da rede de esgotamento sanitário, com destaque para a consolidação de modelos tecnológicos com vistas à remoção conjunta de matéria orgânica e nutrientes (CHRISPIM; SCHOLZ; NOLASCO, 2019; POORTVLIET et al., 2018; LARSEN et al., 2016).

Indo além dos pressupostos que norteiam uma Estação de Tratamento de Esgoto (ETE) como unidade de remoção de poluentes a níveis aceitáveis legalmente, tomando-se por base o relatório mundial nas Nações Unidas sobre o desenvolvimento dos recursos hídricos, de 2017 , entende-se que a melhoria do gerenciamento da qualidade dos efluentes lançados nos corpos d'água contribui significativamente para um desenvolvimento econômico equilibrado com a proteção dos recursos naturais, alinhando-se ao discurso e aos princípios da sustentabilidade, sobretudo, em um cenário mundial de escassez hídrica e energética (ONU, 2019; NASCIMENTO, 2012).

Dessa forma, agregando conceitos introduzidos pela economia circular com vistas a uma gestão de recursos naturais que rompe com o atual padrão linear, baseado na extração, uso e descarte, é possível uma nova abordagem ao emprego dos subprodutos gerados numa ETE, do tipo "berço ao berço" (cradle-to-cradle), pois o que antes era considerado resíduo de um processo passaria a ser considerado como matéria-prima de outro, tal que o fluxo de insumos pudesse ser mantido num ciclo fechado (SILVA; POAGUE; NUNES, 2018).

Nesse sentido, o planejamento das estações de tratamento de esgoto romperia com a antiga visão de que os empreendimentos sanitários são aplicações de alto investimento sem retorno com ações baseadas no modelo de remoção e geração de resíduos, para a adoção das premissas tanto da economia circular como da sustentabilidade, com o uso restaurativo de recursos e de recuperação de produtos agregando valor de mercado (ANDERSON; OTOO; NOLASCO, 2018). Assim, o confronto entre soluções locais e soluções centralizadas e a valorização de técnicas que intensificam a reutilização dos efluentes líquidos e sólidos deverão orientar novas perspectivas (HELLER; NASCIMENTO, 2005; CANO et al., 2019; CANO et al., 2020).

$\mathrm{Na}$ busca pela consolidação dessa nova abordagem, as estações de tratamento de esgoto registraram, ao longo do tempo, a adoção de novas tendências de desenvolvimento tecnológico (LENART-BORON et al., 2019; MORIHAMA et al., 2018; MAKISHA; GEORGINA, 2017), das quais se destacam estas: 
a) Eficiência: atendimento a padrões de qualidade cada vez mais restritivos, tratando esgoto a taxas cada vez maiores.

b) Compacidade: ocupar o menor espaço necessário para o desenvolvimento dos processos.

c) Automação: redução da incidência de falhas causadas pela atividade humana.

d) Economia de energia: tecnologias que demandam baixo consumo energético.

e) Produção e processamento de lodo: minimizar a geração de lodo de excesso, assegurando sua higienização e mineralização avançada.

f) Diminuição na produção de lodo.

g) Controle de odores: coberturas e processos de desodorização dos gases provenientes do processamento do esgoto.

h) Sustentabilidade: adoção de tecnologias que equilibrem operação e manutenção, oferecendo estabilidade à estação.

i) Novos materiais e métodos construtivos: minimizar custos de implantação e aumentar a vida útil das instalações.

Com base nesse novo paradigma, a partir de 2012, diversas organizações internacionais, a exemplo da International Water Association (IWA), da Water Environment Federation (WEF) e da Water Research Foundation (WRF/WERF), passaram a propor a questão do tratamento de esgoto como fonte de recursos recuperáveis amplamente disponíveis e valiosos, sob uma nova perspectiva para as ETEs, as quais passariam a ser vistas e geridas como Unidade de Recuperação de Recursos (Water Resource Recovery Facility). No Brasil, grupos de pesquisa em saneamento nas universidades UFMG, UFC, UFMS, UFPE, UFRJ, USP e ISAE/FGV formaram uma rede de estudos, em 2017, vinculados ao Instituto Nacional de Ciência e Tecnologia em ETEs Sustentáveis (INCT ETEs Sustentáveis), denominando essa abordagem, as práticas e as tecnologias por Estação de Tratamento de Esgoto Sustentável (SOLON et al., 2019; CORNEJO et al., 2019; MOTA, 2018; GOLDSTEIN, 2018).

Em decorrência desse movimento, a literatura especializada tem reportado, nos últimos 20 anos, numerosos estudos sobre a otimização do desempenho de ETEs convencionais por meio da integração de novas tecnologias e de novos arranjos de processos que caracterizam essa transição rumo a uma abordagem sustentável.

Entre essas novas tecnologias desenvolvidas que permitem introduzir as ideias de sustentabilidade a uma ETE, pode-se citar: a variante do processo de lodos ativados chamado de UCT (University of Cape Town), no qual a recuperação de fósforo é potencializada permitindo seu posterior uso como adubo orgânico; o reator de geração de estruvita, um minério de interesse agrícola formado por nitrogênio e fósforo removidos do esgoto; o emprego de lodo gerado nas ETEs como adubo na agricultura ou em processos de geração de energia; o uso de processos de filtração em membranas, como osmose-reversa, na obtenção de água de reúso; entre outros (ROLIN et al., 2016; CASTRO et al., 2014; BITTENCOURT; AISSE; SERRAT, 2017; SOLON; JIA; VOLCKE, 2019).

Portanto, nesse novo paradigma, uma ETE Sustentável baseia seu gerenciamento integrando todos os subprodutos gerados no processo de forma a reutilizá-los ou reprocessá-los, seja como fonte alternativa de água, aproveitamento do potencial de geração de energia ou recu- 
peração de nutrientes (CHENG et al., 2019); desse modo, alinha-se ao conceito do "berço ao berço", inspirando a criação de um sistema produtivo circular, com capacidade de transformar o esgoto em recursos com valor agregado, e rompendo com o modelo atual, cujo objetivo se assenta no simples atendimento a padrões legais de lançamento em corpo receptor (CHRISPIM; SCHOLZ; NOLASCO, 2020).

Nesse contexto, no que tange, por exemplo, ao mercado de nutrientes (nitrogênio e fósforo), no ano de 2011, a demanda mundial de fósforo foi de aproximadamente 15 milhões de toneladas, e estimativas indicam que em 2050 esse valor será da ordem de 110 milhões de toneladas; há estudos que indicam que o fósforo presente nas fezes humanas supriria cerca de $22 \%$ dessa demanda, portanto, o lodo gerado nas ETEs se apresenta com um grande potencial para abastecer esse mercado (PANTANO et al., 2016).

Estudos apresentados por Matos e Paternostro (2018) indicam que o Brasil possui 673 ETEs operando com reatores anaeróbios com potencial para geração de energia, porém, a grande maioria não realiza essa atividade, um quadro que tende a se modificar graças a uma parceria firmada com o governo alemão com o projeto Probiogás, cujo propósito é fomentar a geração de energia limpa e a diminuição da emissão de metano.

Estimativas realizadas pelo INCT - ETEs Sustentáveis, com base em uma ETE de pequeno porte (6,3 milhões de habitantes), apontam que a valorização do esgoto no Brasil poderia contribuir anualmente com pelo menos 11 bilhões de metros cúbicos de água de reúso, $206 \mathrm{MW} / \mathrm{d}$ de energia proveniente do biogás, 8.500 toneladas de nitrogênio, 6.400 toneladas de fósforo e 6.400 toneladas de lodo higienizado (MOTA, 2018).

Por causa das vantagens proporcionadas por essa nova abordagem no tratamento do esgoto, o estudo de recuperação de recursos presentes em águas residuais tem se tornado um campo de pesquisa promissor. Nesse sentido, de acordo com Heller e Nascimento (2005), a identificação das formas e veículos disponíveis para a disseminação do conhecimento produzido e para a transferência de tecnologia e a identificação de periódicos associados ao tema devem atuar como multiplicadores na compreensão, na formação de pessoal e no de novas modalidades e tópicos envolvidos com o assunto.

Contudo, há de se compreender a existência de barreiras em nível tecnológico, financeiro e de governança a serem superadas, as quais possuem como principais atores o meio acadêmico e os investidores (POSSETTI, 2019).

O trabalho de prospecção e de monitoramento da tecnologia pode, portanto, contribuir com a construção de um mapa conceitual de informações e de conhecimentos inerentes ao assunto, permitindo identificar, entre as diversas informações do universo prospectado, as tendências relevantes e os sinais de mudança no ambiente, reduzindo o grau de incerteza nas ações de Pesquisa e Desenvolvimento (P\&D) (AMPARO; RIBEIRO; GUARIEIRO, 2012; BORSCHIVER; ALMEIDA; ROITMANT, 2008).

O presente manuscrito apresenta um estudo de prospecção tecnológica e científica com o objetivo de mapear, em um espaço temporal, as publicações existentes na área, por meio da plataforma Web of Science (WOS). Em adição foram utilizadas as bases de dados patentárias, com vistas a essa nova abordagem de economia circular e sustentabilidade aplicada à estação de tratamento de esgoto, com o propósito de analisar as perspectivas acerca do tema. 


\section{Metodologia}

O escopo da estratégia de pesquisa em termos do volume da produção acadêmica e científica visou a garantir que os artigos mais relevantes fossem localizados e processados. Para tanto, empregou-se a ferramenta de busca em base de dados Web of Science (WOS), a fim de selecionar uma expressão de busca que fosse representativa para a prospecção tecnológica almejada.

A WOS é uma das mais completas bases de dados disponível, tratando-se de um portal que agrega o conjunto de dados bibliográficos e citação, indicadores bibliométricos, compiladas pela Clarivate Analytics, a qual contém informações de revistas e de congressos científicos em todas as áreas do conhecimento. As principais revistas do setor do saneamento e engenharia ambiental podem ser acessadas via WOS, por exemplo: Water Research; Water Science and Technology; Water Environment Research; Journal American Water Works Association - AWWA; além de diversos títulos da American Society of Civil Engineers (ASCE), Revista Engenharia Sanitária e Ambiental, entre outras.

As pesquisas no site da WOS foram realizadas pelo método de busca avançada, combinando mais de um termo característico ao assunto-alvo e fixando o Título como rótulo do campo de busca. Primeiramente, definiu-se o intervalo de tempo compreendendo o período de 1999 a 2019 e, em seguida, foram estabelecidos descritores associados ao estudo em questão, optando-se pelo uso do operador booleano OU (OR) quando do uso da palavra "esgoto" para cobrir os eventuais termos equivalentes comumente observados nos artigos acadêmicos nacionais $e$ internacionais. A Tabela 1 resume os descritores aplicados nas buscas.

Tabela 1 - Descritores aplicados nas buscas da plataforma WOS

Modelo tradicional de ETE

wastewater treatment

OR effluent treatment

OR sewage treatment

\section{Novo paradigma aplicado a ETE}

Water Resource Recovery Facility

wastewater nutrient recovery OR wastewater nitrogen recovery $\mathrm{OR}$ wastewater phosphorus recovery

sewage reuse OR effluent reuse OR wastewater reuse sewage biogas OR wastewater biogas

Fonte: Elaborada pelos autores deste artigo (2019)

A prospecção patentária foi realizada em cinco escritórios de bases de dados gratuitos disponíveis na internet: Instituto Nacional da Propriedade Industrial (INPI); World Intellectual Property Organization (WIPO); Google Patents; Banco de Patentes Latino-Americanos (LATIPAT); e European Patent Office (EPO).

Foi realizada a pesquisa avançada na seção Títulos e Resumo; quanto aos descritores empegados na busca, optou-se pelo uso do operador booleano E com o intuito de associar a ação-alvo com o termo esgoto e, como já esclarecido, o uso do operador booleano OU, para cobrir os adjetivos comuns à palavra esgoto. A Tabela 2 apresenta os termos relacionados. 
Tabela 2 - Descritores aplicados nas prospecções patentárias

Descritores no idioma português

reúso e esgoto ou reúso e efluente ou reúso e água residuária;

recuperação e biogás e esgoto ou recuperação e biogás e efluente ou recuperação e biogás e águas residuárias;

recuperação e nutrientes e esgoto ou recuperação e nutrientes e efluente ou recuperação e nutrientes e água residuária;

recuperação e nitrogênio e esgoto ou recuperação e nitrogênio e efluente ou recuperação e nitrogênio e água residuária;

recuperação e fósforo e esgoto ou recuperação e fósforo e efluente ou recuperação e fósforo e água residuária

\section{Descritores no idioma inglês}

reuse and sewage or reuse and effluent or reuse and wastewater;

recovery and biogas and sewage or recovery and biogas and effluent or recovery and biogas and wastewater;

recovery and nutrients and sewage or recovery and nutrients and effluent or recovery and nutrients and wastewater;

recovery and nitrogen and sewage or recovery and nitrogen and effluent or recovery and nitrogen and wastewater;

recovery and phosphorus and sewage or recovery and phosphorus and effluent or recovery and phosphorus and wastewater

Fonte: Elaborada pelos autores deste artigo (2019)

As informações obtidas foram organizadas em tabelas ou em gráficos de forma a permitir a observação da evolução técnico-científica e tecnológica desse tema ao longo dos anos.

\section{Resultados}

A seguir, são apresentados os resultados obtidos nas buscas e nas prospecções, bem como as inferências, as análises $e$ as avaliações que se permitiram obter.

\subsection{Análise da Evolução da Produção Científica}

Com base no uso de descritores associados ao modelo tradicional de tratamento de esgoto, foram obtidos 23.819 registros, demonstrando uma tendência crescente ao longo dos anos no número de publicações, com uma relativa queda observada em 2019 (ressalta-se que muitos artigos ainda estão em fase de avaliação e outros ainda poderão ser produzidos), tendo a China com o maior número de publicações, seguida pelos EUA, Índia e Espanha; o Brasil encontra-se na quinta posição dessa lista com 956 publicações. O modelo de artigo científico foi a forma predominante de apresentação das pesquisas, e o periódico Water Science and Technology apresentou o maior número de registros. A Figura 1 apresenta uma série histórica dos dados gerados pela ferramenta WOS. 
Figura 1 - Série histórica com os descritivos do modelo tradicional de tratamento de esgoto

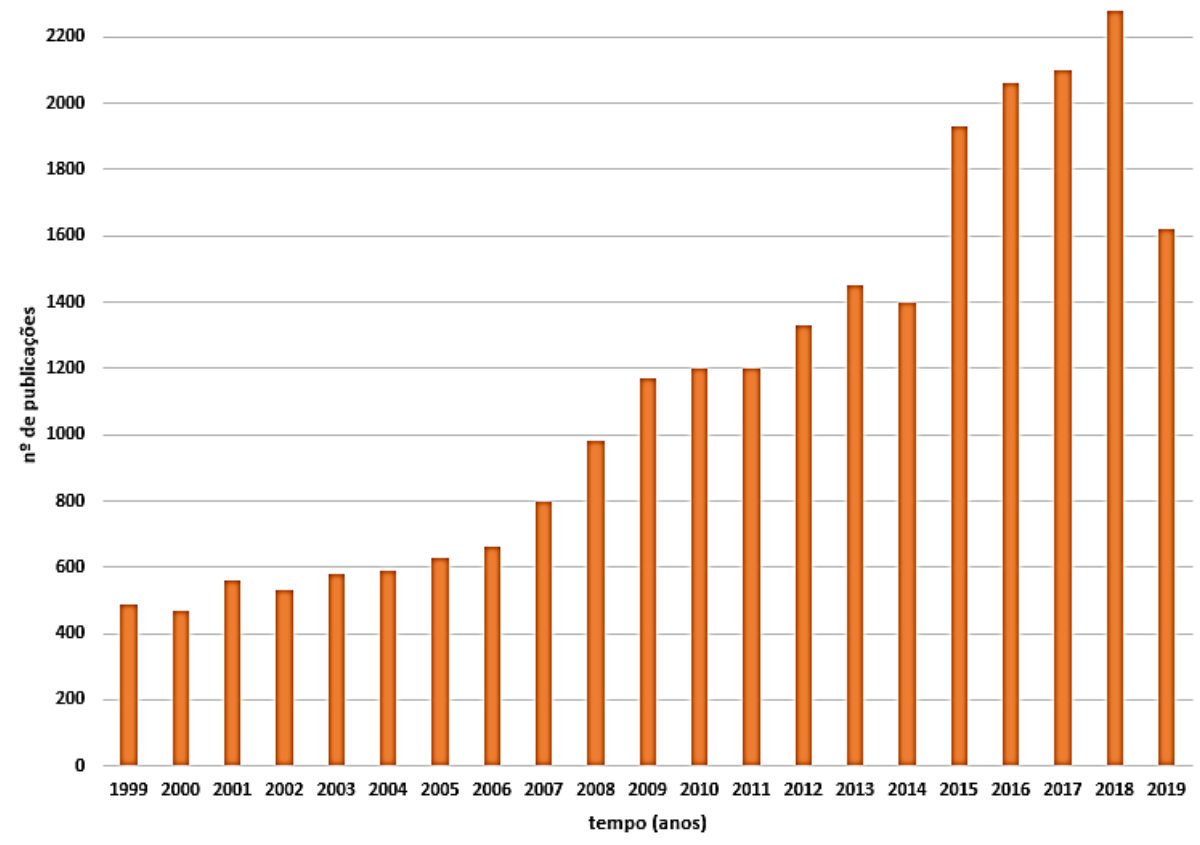

Fonte: Elaborada pelos autores deste artigo (2019)

Um ponto a ser considerado diante do grande número de publicações sobre o tema e do ranking de países em número de registro obtido pelo uso da plataforma WOS é o reflexo do nível de investimento em inovação praticado por cada país, já que, de acordo com o Fórum Econômico Mundial, em 2018, os EUA investiram US\$ 476,5 bilhões anuais, e a China, US\$ 370,6 bilhões, perfazendo $62 \%$ do investimento global na área. O Brasil aparece em nono lugar, investindo US $\$ 42,1$ bilhões ao ano em pesquisa e desenvolvimento, ou 2,3\% do investimento global. O país fica atrás do Reino Unido, mas à frente de países como Canadá, Austrália e Holanda (WORD ECONOMIC FORUM, 2019).

O destaque da atuação chinesa pode ser entendido como fruto da iniciativa do governo em investir na proteção ambiental com ênfase na sustentabilidade. O progresso ecológico da China, alinhado com suas condições políticas, econômicas, sociais, culturais e ecológicas, tem enfatizado a aplicação abrangente de várias ferramentas, imbuindo cada aspecto da produção e da vida com o conceito de desenvolvimento verde (HUIYUAN, 2019). Ainda corroborando com a liderança da China frente aos EUA, o importante periódico Nature publicou o Indice Nature, um sistema sofisticado e complexo de aferições, criado e mantido pela revista, baseado na publicação de artigos originais naquelas que são consideradas as 68 revistas científicas mais importantes do mundo, levando em consideração, portanto, cerca de 60 mil artigos por ano. De acordo com esse índice, os EUA seguem líderes, porém, a China vem em segundo, apresentando um crescimento de 37\% entre 2012 e 2014, enquanto os EUA decaíram, no mesmo período em 4\% (NATURE INDEX, 2019).

Partindo desse cenário em pesquisas sobre tratamento de esgoto sob a ótica tradicional, foi possível avaliar a inserção da produção acadêmica dos estudos associados ao novo paradigma no tratamento de esgoto. Para tanto, foram executadas as buscas com os descritores apresentados na Tabela 1, sendo os resultados apresentados nas Figuras 2, 3, 4 e 5. 
Figura 2 - Série histórica com descritor associado ao termo "Resource Recovery Facility"

$$
12
$$

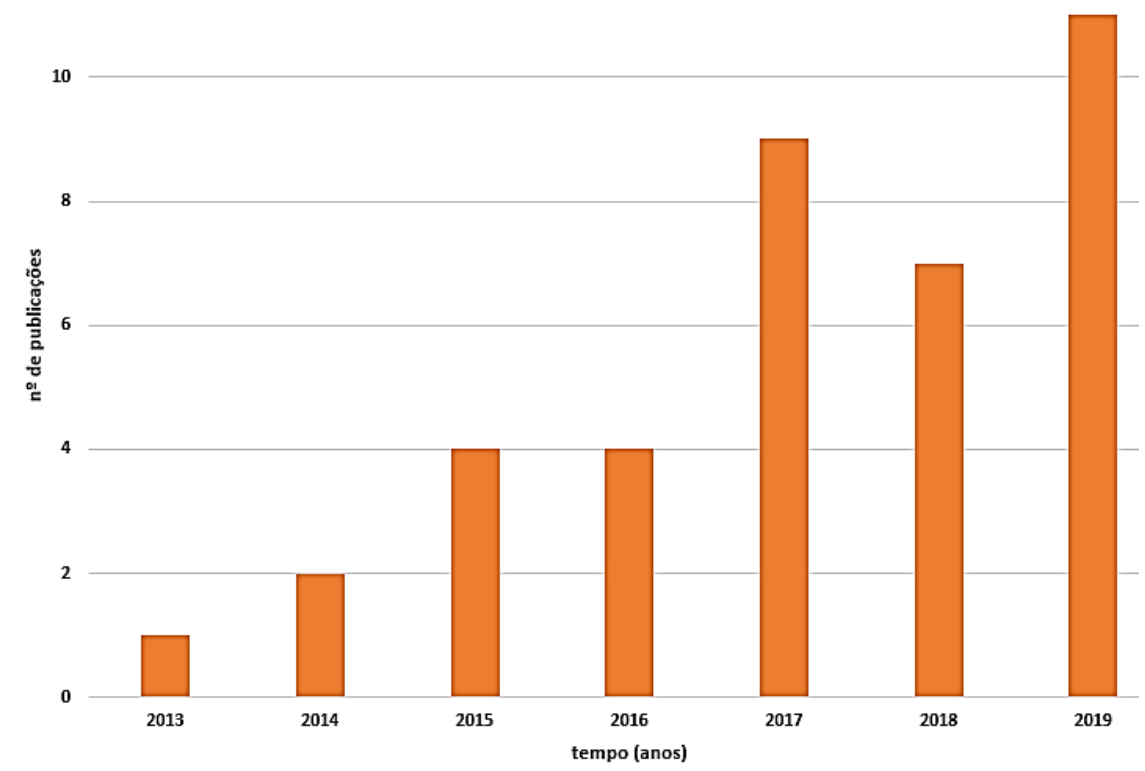

Fonte: Elaborada pelos autores deste artigo (2019)

De acordo com a Figura 2, a busca resultou em um número bem mais reduzido de registros de artigos publicados, 38, com uma tendência crescente (exceto em 2018 quando houve uma leve retração), tendo a primeira publicação nessa plataforma em 2013, posterior à criação da definição pela IWA, sendo, de fato, um assunto recente no meio acadêmico, já que uma pesquisa feita com os descritores para o modelo tradicional aponta para a primeira publicação existente no WOS datando de 1995. Em relação ao país/região de origem das publicações, nota-se o predomínio dos EUA e, na sequência, o Canadá, a Bélgica e a Espanha, não tendo o registro da contribuição do Brasil nos arquivos da plataforma. O modelo de artigo científico manteve-se como a forma predominante de apresentação dos resultados de pesquisas, e o periódico Water Environment Research com o maior número de registros.

Figura 3 - Série histórica com descritores associados ao termo "recovery"

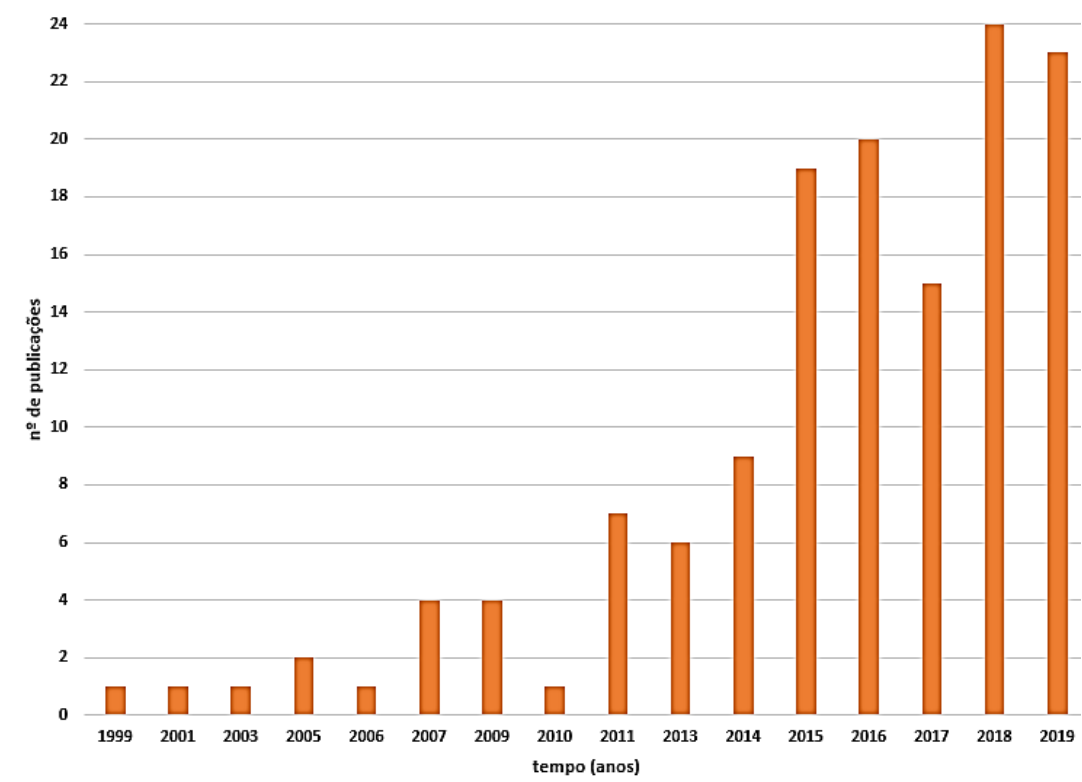

Fonte: Elaborada pelos autores deste artigo (2019) 
A Figura 3 apresenta 138 publicações, com um considerável aumento de registros a partir de 2015, estando a China em primeiro lugar em número de trabalhos publicados, seguida dos EUA, Austrália e África do Sul, e o Brasil ocupando a $7^{a}$ posição com quatro contribuições. O periódico Bioresource Technology lidera o ranking de publicações, tendo o modelo de artigo científico como a forma predominante de apresentação dos estudos.

Ainda no contexto de ETE sustentável, a Figura 4 exibiu 1.602 registros de artigos associados ao reúso de esgoto, tendo pouca variação do número de publicações de 1999 a 2014 (exceção feita aos anos de 2000 e 2002), com um relativo aumento a partir de 2015, sendo que o ano de 2016 foi o que apresentou o maior número de trabalhos publicados. Repete-se a liderança da China, seguida dos EUA, Espanha e Itália; o Brasil ocupa a quinta posição do ranking com 79 contribuições de estudos. O periódico Water Science and Technology foi o que apresentou maior número de publicações na divulgação dos estudos.

Figura 4 - Série histórica com descritores associados ao termo "reuse"

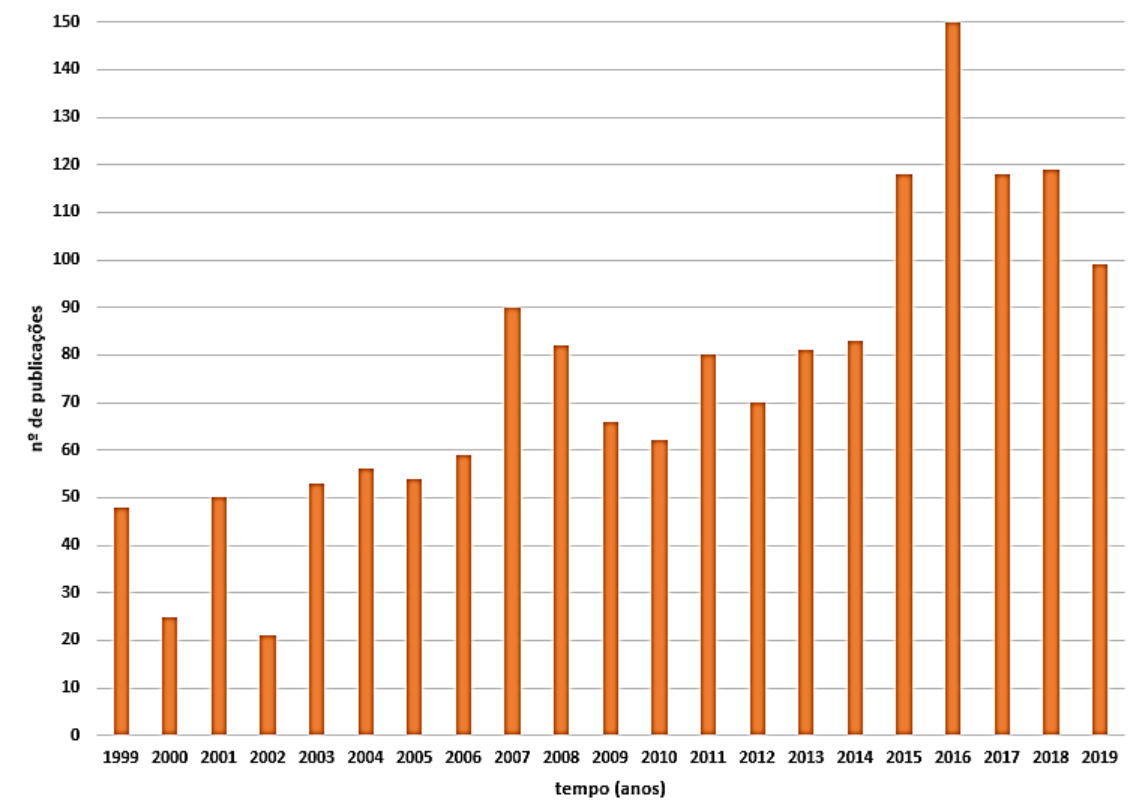

Fonte: Elaborada pelos autores deste artigo (2019)

Com os descritores sewage biogas OR wastewater biogas, a ferramenta WOS apresentou 418 registros, com um considerável aumento no número de publicações a partir de 2013, tendo em 2018 o ano com mais contribuições. A China aparece, também, em primeiro lugar, seguida de Espanha, Brasil (29 publicações) e EUA. O periódico Bioresource Technology possui o maior número de trabalhos, e o modelo de artigo científico mantém-se como a forma predominante de divulgação da pesquisa. A Figura 5 apresenta a série histórica de publicação. 
Figura 5 - Série histórica com descritores associados ao termo "biogas"

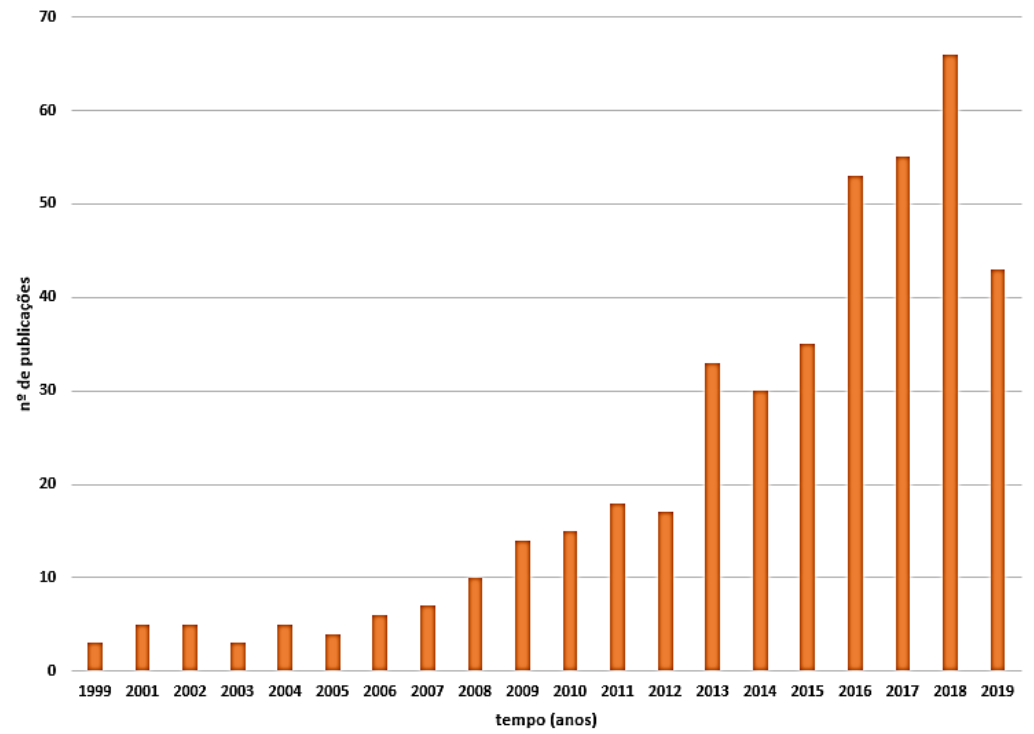

Fonte: Elaborada pelos autores deste artigo (2019)

De uma forma geral, a pesquisa com os descritivos sewage reuse OR effluent reuse OR wastewater reuse apresentaram o maior número de publicações, indicando uma tendência nesse segmento.

Nesse sentido, em relação à perspectiva sobre o campo de pesquisa em reúso de esgoto no Brasil, é possível citar as iniciativas pioneiras como a da Companhia de Saneamento Básico do Estado de São Paulo (SABESP) - concessionária de saneamento de São Paulo - já que, desde 1998, essa empresa implementou adequações na Estação de Tratamento de Esgoto de Jesus Netto, na região do Bairro Ipiranga, região central da cidade de São Paulo, transformando-a em uma estação para produção de água de reúso. Atualmente são produzidos, em média, 502 litros de água por segundo pelas estações Jesus Netto, Barueri, Parque Novo Mundo, São Miguel e $\mathrm{ABC}$, com fornecimento externo atendendo tanto ao setor industrial e municipal como em demandas internas da própria empresa de saneamento. Destaca-se o empreendimento concebido junto à ETE ABC, pois anexo a essa estação foi desenvolvido o projeto Aquapolo, inaugurado em 2010 por meio da parceria entre uma empresa privada e a Sabesp. O empreendimento inovador recebe o efluente da Estação de Tratamento de Esgoto $\mathrm{ABC}$, e, por meio de processos físico-químicos avançados, essa estação tem capacidade de produzir cerca de 1.000 litros de água de reúso de elevada qualidade para abastecer o Polo Petroquímico de Capuava, em Mauá - SP (SABESP, 2019).

Contudo, deve-se ressaltar o hiato entre o meio acadêmico e o mercado de aplicação e normativo, já que o País carece de uma legislação nacional para nortear o uso desse produto, tendo, atualmente, apenas a Norma ABNT/NBR 13969/97 e a Resolução CNRH n. 54 (28711/2005), além de alguns decretos municipais específicos para lavagem de ruas públicas, passeios e irrigação de praças (PHA-EPUSP, 2019).

O Brasil merece destaque como representante dos países com economia emergente, aparecendo em quinto lugar em número de publicações associadas ao modelo tradicional; em sétimo lugar em publicações sobre recuperação de nutrientes; em quinto lugar para publicações sobre reúso de efluentes; e em terceiro lugar sobre produção de biogás a partir do esgoto. 
Ainda em relação ao Brasil, sobre a sua ausência na lista de publicações com o descritor Resource Recovery Facility (Figura 2), avaliando-se sua boa participação nas pesquisas com os demais descritores, pode-se supor que o meio acadêmico brasileiro não tenha adotado o termo proposto pela IWA, optando pela expressão Estação de Tratamento de Esgoto Sustentável para designar esse novo paradigma, tal qual o INCT ETE Sustentável sugere.

Ponto importante, contudo, ao se limitar a análise ao território brasileiro, é o fato de que os maiores entraves nas questões aqui apresentadas ainda se assentam na baixa capacidade do País em investir na coleta e no tratamento dos esgotos. Outrossim, o atraso que impera no atendimento das metas de universalização do esgotamento sanitário restringe as preocupações $e$ as ações predominantemente para demandas na melhoria da colossal quantidade de esgotos despejados continuamente nos corpos receptores, ao invés de se organizar estratégias mais atuais que visem à recuperação dos elementos presentes, reinserindo-os no mercado como recursos naturais.

\subsection{Análise da Participação Patentária}

A Tabela 1 apresenta o número de patentes encontradas pela busca nos escritórios selecionados.

Tabela 1 - Número de patentes encontradas pela busca em bancos de dados nacionais e internacionais

\begin{tabular}{|c|c|c|c|c|c|}
\hline Descritores & INPI & LATIPAT & $\begin{array}{l}\text { GOOGLE } \\
\text { PATENTS }\end{array}$ & WIPO & EPO \\
\hline $\begin{array}{l}\text { reúso e esgoto ou reúso e efluente } \\
\text { ou reúso e água residuária }\end{array}$ & 0 & 61 & 239.281 & 4.243 & 2.897 \\
\hline $\begin{array}{l}\text { recuperação e biogás e esgoto ou } \\
\text { recuperação e biogás e efluente ou } \\
\text { recuperação e biogás e águas residuárias }\end{array}$ & 4 & 79 & 12.161 & 9.077 & 1.721 \\
\hline $\begin{array}{l}\text { recuperação e nutrientes e esgoto ou } \\
\text { recuperação e nutrientes e efluente ou } \\
\text { recuperação e nutrientes e água residuária }\end{array}$ & 0 & 2 & 67.083 & 12.028 & 51 \\
\hline $\begin{array}{l}\text { recuperação e nitrogênio e esgoto ou } \\
\text { recuperação e nitrogênio e efluente ou } \\
\text { recuperação e nitrogênio e água residuária }\end{array}$ & 0 & 3 & 147.940 & 56.810 & 479 \\
\hline $\begin{array}{l}\text { recuperação e fósforo e esgoto ou } \\
\text { recuperação e fósforo e efluente ou } \\
\text { recuperação e fósforo e água residuária }\end{array}$ & 0 & 3 & 84.925 & 1.041 & 13 \\
\hline Total & 4 & 148 & 551.390 & 83.199 & 5.161 \\
\hline
\end{tabular}

Fonte: Elaborada pelos autores deste artigo (2019)

A pesquisa nos bancos de dados patentários desses cinco escritórios exibiu 639.902 documentos contendo um dos descritores selecionados, evidenciando uma grande participação na construção tecnológica referente à proposição de produtos que atuam no contexto temático deste trabalho. 
Interessante notar que do total de exibições, cerca de $38 \%$ dos documentos são cobertos pelos descritores associados ao reúso de esgoto, evidenciando a mesma tendência quando da prospecção em publicações acadêmicas; ressaltando a prevalência desse subproduto do tratamento de esgoto na inserção do mercado consumidor.

Como era de se esperar, organizações como Google Patents e WIPO apresentaram a maior quantidade de citações, uma vez que são bases de dados gratuitas e de ampla abrangência internacional. As demais bases possuem um recorte mais restrito, a LATIPAT cuida da proteção intelectual de invenções de 18 países da América Latina, a EPO tem ação predominantemente europeia, e o INPI é uma base de dados de documentos estritamente brasileiros.

A baixa incursão em registros dos descritivos na agência brasileira, INPI, pode ser em função da burocracia na legislação que rege a obtenção de patentes e do tempo de tramitação do processo pelo órgão. Dados disponibilizados pela Organização Mundial da Propriedade Intelectual (OMPI), no documento World Intellectual Property Indicators 2018, apontam para o fato de o Brasil ter o pior desempenho entre os 76 principais escritórios do mundo responsáveis pelo registro de patentes e propriedade intelectual. Segundo o estudo, em média, a avaliação de uma solicitação de patentes no INPI leva 95 meses para ser concluída, enquanto na China ou na Europa, o prazo é de 22 meses, e na Rússia, apenas nove meses (WIPO, 2018).

Outra ferramenta disponível na plataforma é a delimitação do espaço-tempo para que ocorra a pesquisa. A Tabela 2 apresenta os resultados obtidos.

Tabela 2 - Distribuição de pedidos de patentes com base no intervalo de tempo (1999 a 2019)

\begin{tabular}{|c|c|c|c|}
\hline \multicolumn{4}{|c|}{ DESCRITORES } \\
\hline Período & $\begin{array}{c}\text { RECUPERAÇÃO E } \\
\text { NUTRIENTES E ESGOTO }\end{array}$ & $\begin{array}{c}\text { RECUPERAÇÃO E } \\
\text { NUTRIENTES E EFLUENTE }\end{array}$ & $\begin{array}{c}\text { RECUPERAÇÃO E } \\
\text { NUTRIENTES E ÁGUA RESIDUÁRIA }\end{array}$ \\
\hline 1999 a 2010 & 15.313 & 12.273 & 8.482 \\
\hline 2011 a 2019 & 27.283 & 7.143 & 12.308 \\
\hline
\end{tabular}

Fonte: Elaborada pelos autores deste artigo (2019)

Os primeiros 11 anos exibiram 36.068 pedidos de patentes e os nove anos seguintes, 46.734 pedidos, com uma média anual de 3.279 para o primeiro período e 5.193 para o segundo, demonstrando evolução na produção e inovação tecnológica nesse segmento, e se mostrando similar ao observado na produção acadêmica, já que, analisando as Figuras 3, 7, 9 e 11, pode-se observar que é a partir de 2015 que se nota um aumento de registros de trabalhos científicos sobre esse tema, novamente, evidenciando a tendência de crescimento, bem como a condição promissora de se investir em pesquisas/inovações na área de reaproveitamento de subprodutos gerados no tratamento de esgoto. 


\section{Considerações Finais}

Com a presente contribuição, procurou-se apresentar a prospecção tecnológica e científica referente a um tema relativamente novo na academia, baseado no conceito de Unidade Recuperadora de Recursos - ETEs Sustentáveis, em que os subprodutos gerados em uma estação de tratamento de esgoto se tornam matéria-prima dotada de valor de mercado.

Com base nos resultados referentes às buscas feitas na ferramenta WOS, pode-se constatar o predomínio da China, seguida dos EUA, em termos de número de publicações em periódicos indexados, com uma importante participação brasileira, figurando entre os 10 primeiros países do mundo no ranking de publicações. É possível observar que esse interesse do meio acadêmico tem um aumento significativo a partir de 2015.

Os assuntos correlatos ao conceito de unidades de recuperação aqui perscrutado evidenciam uma tendência positiva em relação às pesquisas na área, com ênfase no aproveitamento de esgoto tratado (reúso de água), porém, com inserção ainda pequena quando comparada ao universo de publicações acadêmicas vinculadas com o modelo atual de tratamento de esgoto, baseado na remoção de poluentes.

No que tange à pesquisa feita em base de dados patentárias, observou-se um número considerável de registros com descritores que caracterizam o tema deste estudo, verificando o predomínio do idioma inglês nos registros de pedidos de patentes, bem como, a exemplo do verificado no campo literário, o ano de 2015 como referência para início da escalada em termos numéricos das citações.

Tomando por base o cenário descrito neste estudo, pode-se concluir que o tema é inovador e promissor na medida em que o paradigma da sustentabilidade torna-se cada vez mais necessário nas estruturas básicas de uma organização (economia, sociedade/saúde pública e meio ambiente), e o esgotamento de recursos naturais renováveis e não renováveis reflete a necessidade de adoção de um novo modelo de gestão em que a questão do reaproveitamento/ reúso de subprodutos seja posta em pauta, tanto em termos de políticas públicas como no meio acadêmico, empresarial e social.

\section{Referências}

AMPARO, K. K.; RIBEIRO, M. C. O.; GUARIEIRO, L. L. N. Estudo de caso utilizando mapeamento de prospecção tecnológica como principal ferramenta de busca científica. Perspectivas em Ciência da Informação, Minas Gerais, v. 17, n. 4, p. 195-209, 2012.

ANDERSON, K.; OTOO, M.; NOLASCO, M. Innovative sanitation approaches could address multiple development challenges. Water Science and Technology, [s.l.], v. 77, p. 855-858, 2018.

BITTENCOURT, S.; AISSE, M. M.; SERRAT, B. M., Gestão do uso agrícola do lodo de esgoto: estudo de caso do estado do Paraná, Brasil, Revista Engenharia Sanitária Ambiental, [s.l.], v. 22, n. 6, p. 1129-1139, 2017.

BORSCHIVER, S.; ALMEIDA, L. F. M.; ROITMANT, T. Monitoramento Tecnológico e Mercadológico de Biopolímeros. Revista Polímeros: Ciência e Tecnologia, [s.l.], v. 18, n. 3, p. 256-261, 2008. 
BRASIL. Resolução n. 54, de 28 de novembro de 2005. Brasília, DF: Ministério do Meio Ambiente, Conselho Nacional de Recursos Hídricos, 2005.

CANO, V. et al. Influence of recirculation over COD and N-NH4 removals from landfill leachate by horizontal flow constructed treatment wetland. International Journal of Phytoremediation, [s.l.], v. 20, p. 998-1004, 2018.

CANO, V. et al. Nitrification in multistage horizontal flow treatment wetlands for landfill leachate treatment. Science of The Total Environment, [s.l.], v. 704, p. 135376, 2020.

CASTRO, S. R. et al. Precipitação química de estruvita: Recuperação de nutrientes em reator cônico de leito fluidizado utilizando magnésia industrial de baixo custo, Revista Engenharia Sanitária Ambiental, [s.l.], v. 20, n. 2, p. 259-268, 2014.

CHENG, T. et al. Monitoring influent measurements at water resource recovery facility using datadriven soft sensor approach. IEEE Sensors Journal, [s.l.], v. 19, n. 1, p. 342-352, 2019.

CHRISPIM, M. C.; SCHOLZ, M.; NOLASCO, M. A. Phosphorus recovery from municipal wastewater treatment: Critical review of challenges and opportunities for developing countries. Journal of Environmental Management, [s.l.], v. 248, p. 1-18, 2019.

CHRISPIM, M. C.; SCHOLZ, M.; NOLASCO, M. A. A framework for resource recovery from wastewater treatment plants in megacities of developing countries. Environmental Research, [s.l.], v. 188, p. 1-14, 2020.

CORNEJO, P. K. et al. Sustainability metrics for assessing water resource recovery facilities of the future. Water Environment Research, [s.l.], v. 91, p. 45-53, 2019.

EPO - EUROPEAN PATENT OFFICE. [Base de dados - Internet]. [2019]. Disponível em: http:// worldwide.espacenet.com. Acesso em: 13 out. 2019.

GOLDSTEIN, N. Codigestion at water resource recovery facilities. BioCycle, [s.l.], v. 59, n. 3, p. 36, 2018.

GOOGLE PATENTS. [Base de dados - Internet]. Acesso à base de dados de patentes americanas, USPTO. [2019]. Disponível em: https://patents.google.com/. Acesso em: 11 out. 2019.

HELLER, L.; NASCIMENTO, N. O. Pesquisa e desenvolvimento na área de saneamento no Brasil: necessidades e tendências. Revista de Eng. Sanitária e Ambiental, [s.l.], v. 10, n. 1, p. 24-35, 2005.

HUIYUAN, Z. A política chinesa para o desenvolvimento sustentável. Portal China hoje. [2019]. Disponível em: http://www.chinahoje.net/a-politica-chinesa-para-o-desenvolvimento-sustentavel/. Acesso em: 20 out. 2019.

INPI - INSTITUTO NACIONAL DA PROPRIEDADE INDUSTRIAL. [Base de dados - Internet]. [2019]. Disponível em: http://www.inpi.gov.br/portal/artigo/busca_de_patentes. Acesso em: 12 out. 2019.

INCT - INSTITUTO NACIONAL DE CIÊNCIA E TECNOLOGIA EM ETEs SUSTENTÁVEIS. O que se pode aproveitar do esgoto? Portal INCT ETEs Sustentáveis. [2019]. Disponível em: https:// etes-sustentaveis.org/?p=3953. Acesso em: 10 set. 2019.

LATIPAT - BANCO DE PATENTES LATINO-AMERICANOS. [Base de dados - Internet]. [2019]. Disponível em: http://lp.espacenet.com. Acesso em: 12 out. 2019. 
LARSEN, T. A. et al. Emerging solutions to the water challaenger of an urbanizing world. Science, [s.l.], v. 352, n. 6.288, p. 928-933, 2016.

LENART-BORON, A. et al. The effect of a sewage treatment plant modernization on changes in the microbiological and physicochemical quality of water in the receiver. Archives or Environmental Protection, [s.l.], v. 45, n. 2, p. 37-49, 2019.

MAKISHA, N.; GEORGINA, E. Scientific approach and practical experience for reconstruction of waste water treatment plants in Russia. In: CONFERENCE ON ADVANCED IN ENERGY SYSTEMS AND ENVIRONMENTAL ENGINEERING (ASEE), Poland, 2017. Anais [...]. Poland, 2017.

MATOS, M. D.; PATERNOSTRO, A. G. Pesquisa exploratória de tecnologias para geração de energia a partir do tratamento de efluente líquido. Caderno de Prospecção, Salvador, v. 11, n. 1, p. 114126, 2018.

MORIHAMA, A. C. D. et al. Desenvolvimento de metodologia para o planejamento de modernização de estações de tratamento de esgoto. In: $29^{\circ}$ CONGRESSO NACIONAL DE SANEAMENTO E MEIO AMBIENTE (AESABESP/FENASAN), São Paulo, 2018. Anais [...]. São Paulo, 2018.

MOTA, C. ETEs sustentáveis - os desafios e as perspectivas da valorização de subprodutos e sua viabilidade financeira. In: VII DIÁLOGOS DO SANEAMENTO - ETE'S SUSTENTÁVEIS: APROVEITAMENTO DO LODO. Porto Alegre, 2018. Anais [...]. Porto Alegre, 2018. Disponível em: http://www.abes-rs.org.br/novo/index.php?p=evento_materiais\&ref=93. Acesso em: 15 set. 2019.

NASCIMENTO, E. P. Trajetória da sustentabilidade: Do ambiental ao social, do social ao econômico. Revista de Estudos Avançados, [s.l.], v. 26, n. 74, p. 51-74, 2012.

NATURE INDEX. The 2016 tables are based on Nature Index data from 1 January 2015 to 31 December 2015. Portal Nature Index. [2019]. Disponível em: https://www.natureindex.com/annualtables/2016. Acesso em: 20 set. 2019.

ONU-BRASIL. Nações Unidas Brasil, Agenda 2030. Portal Nações Unidas Brasil. [2019a]. Disponível em: https://nacoesunidas.org/pos2015/agenda2030/. Acesso em: 9 set. 2019.

ONU-BRASIL. Nações Unidas Brasil, ODS 6. Portal Nações Unidas Brasil. [2019b]. Disponível em: https://nacoesunidas.org/pos2015/ods6/. Acesso em: 9 set. 2019.

ONU - ORGANIZAÇÃO DAS NAÇÕES UNIDAS. Relatório Mundial das Nações Unidas sobre o desenvolvimento dos recursos hídricos, 2017: Águas residuais: o recurso inexplorado, fatos e números. Portal UNESCODOC - Digital Library. [2019]. Disponível em: https://unesdoc.unesco. org/ark:/48223/pf0000247553_por. Acesso em: 15 set. 2019.

PANTANO, G. et al. Sustentabilidade no uso do fósforo: Uma questão de segurança hídrica e alimentar. Revista Química Nova, [s.l.], v. 39, n. 6, p. 732-740, 2016.

PHA-EPUSP. Legislação sobre reúso de água - Notas de aula disciplina 2548. Portal Escola

Politénica - Depto. Eng. Hidráulica e Ambiental (PHA). [2019]. Disponível em: http://www.pha. poli.usp.br/LeArq.aspx?id_arq=18174. Acesso em: 20 out. 2019.

POORTVLIET, P. M. et al. Acceptance of new sanitation: The role of end-users pro-envinmental personal norms and risk and benefit perceptions. Water Research, [s.l.], v. 131, p. 90-99, 2018. 
POSSETTI, G. O futuro do saneamento na valorização do esgoto. Portal do Saneamento Básico. [2019]. Disponível em: https://www.saneamentobasico.com.br/ saneamento-valorizacao-esgoto/\#: : :text $=$ Nesse $\% 20$ contexto $\% 2 \mathrm{C} \% 20$ surgem $\% 20$ as $\% 20$ esta\%C3\%A7\%C3\%B5es,forma\%20sistem\%C3\%A1tica\%2C\%20integrada\%20e\%20sustent\%C3\%A1vel. Acesso em: 19 out. 2019.

ROLIM, H. O. et al. Qualidade dos efluentes de sistemas de tratamento biológico UASB e UCT para reúso agrícola. Revista em Agronegócio e Meio Ambiente, Maringá, [s.l.], v. 9, n. 2, p. 393-414, 2016.

SABESP - COMPANHIA DE SANEAMENTO BÁSICO DO ESTADO DE SÃO PAULO. Foz do Brasil e Sabesp inauguram o maior projeto de água de reúso do Brasil. Portal da SABESP. [2019]. Disponível em: http://site.sabesp.com.br/site/imprensa/releases-Detalhes. aspx?secaold=193\&id=4893. Acesso em: 12 out. 2019.

SILVA, W. R.; POAGUE, K. I. H. M.; NUNES, J. C. Estudo de viabilidade econômica do aproveitamento comercial de areia retida no tratamento preliminar da ETE Onça - MG. The Journal of Engineering and Exact Sciences, [s.l.], v. 4, n. 4, p. 1-5, 2018.

SOLON, K. et al. Resource recovery and wasterwater treatment modelling. Environmental ScienceWater Research \& Technology, [s.l.], v. 5, n. 4, p. 631-642, 2019.

SOLON, K.; JIA, M.; VOLCKE, E. I. P. Process schemes for future energy-positive water resource recovery facilities. Water Science \& Technology, [s.l.], v. 79, n. 9, p. 1.808-1.820, 2019.

UNESCO - ORGANIZAÇÃO DAS NAÇÕES UNIDAS PARA A EDUCAÇÃO, A CIÊNCIA E A CULTURA. Relatório de ciência da UNESCO: Rumo a 2030, visão geral e cenário brasileiro. Portal UNESCODOC - Digital Library. [2019]. Disponível em: https://unesdoc.unesco.org/ark:/48223/ pf0000235407_por?posInSet=2\&queryId =6e8b4123-9c20-4c42-90c2-2544a296470a. Acesso em: 13 set. 2019.

WEF MoP 35 (Water Environment Federation - Manuals of Practice of the Water Environment Federation), Biofilm Reactors, Mc Graw Hill, 2011.

WIPO - WORLD INTELLECTUAL PROPERTY ORGANIZATION. [Base de dados - Internet]. [2019]. Disponível em: http://www.wipo.int/patentscope/search/en/search.jsf. Acesso em: 11 out. 2019.

WIPO - WORLD INTELLECTUAL PROPERTY ORGANIZATION. World Intellectual Property Indicators 2018. Geneva: WIPO, 2018.

WORD ECONOMIC FORUM. Innovators wanted: these countries spend the most on R\&D. Portal The Word Economic Forum. [2019]. Disponível em: https://www.weforum.org/agenda/2018/12/ how-much-countries-spend-on-r-d/. Acesso em: 15 out. 2019. 


\section{Sobre os Autores}

\section{Fabio Campos}

E-mail: fcampos@usp.br ORCID: http://orcid.org/0000-0002-8117-789X

Doutor em Ciências pela Faculdade de Saúde Pública da USP.

Endereço profissional: Avenida Prof. Almeida Prado, n. 271, Travessa 2, Prédio da Eng. Civil, Laboratório de Saneamento, São Paulo, SP. CEP: 05508-070.

\section{Marcelo A. Nolasco}

E-mail:mnolasco@usp.br ORCID: http://orcid.org/0000-0002-1408-2954

Doutor em Engenharia Civil, ênfase em Engenharia Hidráulica e Saneamento, pela Escola de Engenharia de São Carlos da USP. Professor de Saneamento Ambiental pela Escola de Artes Ciências Humanidades da Universidade de São Paulo.

Endereço profissional: Universidade de São Paulo. Rua Arlindo Bettio, n. 1.000, Ermelino Matarazzo, São Paulo, SP. CEP: 03828-000. 